\title{
5 Research Square

\section{Ratiometric Probe for Rapid Naked Eye Detection of Toxic Hydrazine: Real Time Application in Strip Test, Spray Test and Soil Analysis}

Natarajan Vijay

National Institute of Technology Tiruchirappalli

Sivan Velmathi ( $\sim$ svelmathi@hotmail.com)

National Institute of Technology https://orcid.org/0000-0001-7303-0698

\section{Research Article}

Keywords: Ratiometric probe, hydrazine sensing, colorimetric, rapid response, environmental analysis

Posted Date: August 9th, 2021

DOl: https://doi.org/10.21203/rs.3.rs-758105/v1

License: (c) (1) This work is licensed under a Creative Commons Attribution 4.0 International License.

Read Full License 


\section{Abstract}

Striking colorimetric probe $(\mathrm{CynH})$ for abrupt detection of hydrazine under complete aqueous solution was achieved. The water soluble probe was designed with electron "push-pull" strategy by coupling of 4hydroxy benzaldehyde and 2, 3, 3-trimethylindolinine. The positively charged N-propylated indolinine make the probe completely soluble in water. The probe yields eye catching selective detection of hydrazine over other competing analytes with high sensitivity. Obvious colour change was observed from colourless to appearance of bright pink colour with hydrazine. It reacts quickly with hydrazine within 2 minutes and makes the probe an effective candidate for practical application. The real time application was demonstrated using paper strip to detect hydrazine vapour. This probe is superior to earlier reported probes because of its effective sensing of hydrazine displayed with various applications including realtime strip based sensing, spray test and soil analysis. In all the examinations, the probe yields distinct response with rapid naked eye colour change this overcomes the drawbacks of previous reports.

\section{Introduction}

Hydrazine serves as one of the major reactive base in the field of pharmaceutical chemistry and agriculture industries because of its high alkalinity and reducing capability [1-3]. The repulsion between two nitrogen makes it more reactive in chemical synthesis and reactions. Its extensively high reducing nature promotes scavenging of oxygen from air though it applied to protect metal corrosion [4-7]. It can be absorbed by the human beings easily via oral, transdermal and inhalation because of its completely water soluble nature and can cause severe health effects $[8,9]$. Some health effects due to hydrazine exposure can be highlighted such as fiery irritation to the eyes, inflammation and severe corrosion to the skin [10]. It can be lethal to the living systems due to its extremely high toxicity, expected to cause serious skin allergy, skin burn and respiratory injuries to the skin by direct contact with skin [11, 12]. Exposure to these kind of toxic chemicals for long period of time will leads to anaemia, severe damage to the organs, abnormal changes in the metabolism and even worse can cause cancer [13]. As hydrazine is a potential carcinogen, for the sake of peoples health many government limits threshold limit value of toxic hydrazine in drinking water to be as low as $10 \mathrm{ppb}$ and violation of this can cause mutagenesis and carcinogenic damage to liver, kidney lungs and central nervous system [14-17]. Hence, concern about detection of hydrazine in drinking water stimulated over these years as its large usage in industries and pharmaceuticals $[18,19]$. Conventional detection mostly based on chromatographic, mass and electrochemical approaches handicapped in real time sensing of these toxic analytes due to their complicated detection procedure and tedious sample preparation [20-23]. Recently, colorimetric and fluorometric detection of toxic components in the environment has drastically increased due to their ease in operation and detection methods. Basically, colorimetric and fluorescent probes for hydrazine utilizes strong nucleophilicity of hydrazine to break or bind with the recognition unit to induce significant response [24-27]. In scheme 1 cleavage based and addition based recognition units for hydrazine was summarized [28-30]. In 2016 W Chan et al. reported colorimetric probe for detection of hydrazine with ratiometric response. They have achieved $0.186 \mu \mathrm{M}$ hydrazine detection in $80 \%$ aqueous DMSO medium 
[31]. In 2020, S Wang et al. reported colorimetric and fluorometric probe with 1-8 $\mu \mathrm{M}$ detection limit in acetonitrile solvent medium. The probe yields effective naked eye response with hydrazine [32]. Recently in $2020 \mathrm{Simal-Gandara,} \mathrm{J}$ et al. reported a review that includes recent advancement in hydrazine detection and its application [33].

Sensor platform with organic probes handicapped in real time application due to their limitations such as constrained solvent medium, restricted $\mathrm{pH}$ range and prolonged reaction time. Herein, we have developed new colorimetric probe for effective sensing of hydrazine in complete aqueous medium. The probe yield rapid response towards hydrazine with distinct colour change from colourless to appearance of bright pink colour within few minutes of reaction time. The advantages of the probe was utilized to detect the hydrazine vapour in real time sensing using eco-friendly test strips and soil samples.

\section{Experimental Section}

\section{1. Chemicals and Instruments}

All the reagents and chemicals are obtained from commercial dealers and used to carry out all the experiments. Double distilled water was used for the complete studies. Bruker $500 \mathrm{MHz}$ spectrophotometer for ${ }^{1} \mathrm{H}$ and $125 \mathrm{MHz}$ for ${ }^{13} \mathrm{C}$ was employed to obtain the ${ }^{1} \mathrm{H}$ and ${ }^{13} \mathrm{C}$ NMR spectra by dissolving the samples in $\mathrm{CDCl}_{3}$ or $\mathrm{DMSO}^{-\mathrm{d}_{6}}$ solvent. Absorption spectra were collected through Shimadzu UV-2600.

\section{2. Synthesis of probe}

Synthesis route was outlined in scheme 2 . The detailed synthesis procedure for compound 1 a and compound 2 given in supporting information. Compound 2 (604 mg, 2 mmol, 1 eq.) and acetic anhydride ( $280 \mu \mathrm{L}, 3 \mathrm{mmol}, 1.5$ eq.) were dissolved in DCM and added with trimethylamine ( $420 \mu \mathrm{L}, 3 \mathrm{mmol}, 1.5 \mathrm{eq}$.) and stirred at room temperature under nitrogen for $3 \mathrm{~h}$. After completion of the reaction (followed by TLC) the residue was concentrated on vacuum and purified by silica column chromatography (Hexane: ethylacetate (9:1)) yield: $80 \%(0.6 \mathrm{~g}) .{ }^{1} \mathrm{H}$ NMR $\left(500 \mathrm{MHz}\right.$, DMSO-d $\left.\mathrm{d}_{6}\right): 8.5(\mathrm{~d}, J=15 \mathrm{~Hz}, 1 \mathrm{H}), 8.3(\mathrm{t}, J=5 \mathrm{~Hz}$, 2H), $8.0(\mathrm{~d}, J=5 \mathrm{~Hz}, 1 \mathrm{H}), 7.9(\mathrm{~d}, \mathrm{~J}=5 \mathrm{~Hz}, 1 \mathrm{H}), 7.7(\mathrm{~d}, \mathrm{~J}=20 \mathrm{~Hz}, 1 \mathrm{H}) 7.6(\mathrm{~m}, 2 \mathrm{H}), 7.3(\mathrm{t}, \mathrm{J}=5 \mathrm{~Hz}, 2 \mathrm{H}), 4.7(\mathrm{t}, J$ $=7.5,2 \mathrm{H}), 2.3(\mathrm{~s}, 3 \mathrm{H}), 1.9(\mathrm{q}, J=7.5,3 \mathrm{H}), 1.8(\mathrm{~s}, 6 \mathrm{H}) 1.0(\mathrm{t}, J=7.5,3 \mathrm{H}) \cdot{ }^{13} \mathrm{C} \mathrm{NMR}\left(125 \mathrm{MHz}, \mathrm{DMSO}-\mathrm{d}_{6}\right) \delta$ (ppm): 182.6, 169.3, 154.7, 153.3, 144.4, 141.1, 132.6, 132.5, 130.0, 129.6, 123.6, 123.2, 116.0, 113.2, 52.9, 48.3, 26.1, 22.3, 21.4, 11.2. HR-El Mass: Calculated for $\mathrm{C}_{23} \mathrm{H}_{26} \mathrm{~N}_{2} \mathrm{O}$ [M]: 348.21964; Found 348.15968 (ESI: S1-S6).

\section{3. Photophysical studies}

To carryout photophysical studies standard stock solution of probe CyNH in DMSO was prepared with concentration of $0.0015 \mathrm{M}$ and it is further diluted to lower concentration $(\mu \mathrm{M})$ for sensing studies with double distilled water. All the analytes were dissolved in double distilled water to make $0.0015 \mathrm{M}$ concentration for sensing applications. 


\section{Results And Discussion}

Hydrazine sensing attracts much attention in recent days due to their extensively wide usage in chemical and pharmaceutical industries. In favour to detect the hydrazine contamination in water, we plan to design a small molecule organic probe to detect hydrazine with good selectivity and sensitivity under complete aqueous medium. In order to make water soluble organic system, we design a molecule with "electron push-pull" character. 2, 3, 3-Trimethylindolinine was N-alkylated and fused with 4-hydroxy benzaldehyde to make the water soluble probe (Scheme 2). Hydroxyl group was protected by acetic anhydride in order to tune the selective cleavage with hydrazine. Synthesised probe will react selectively

with hydrazine to form an intermediate (Scheme 3). Finally acetohydrazide will cleave from the probe and colourful chromophore will form with bright pink colour.

It is obvious that, after reaction with probe, hydrazine becomes acetohydrazide and loses its toxicity.

\section{1. Naked eye sensing studies}

Herein, the synthesised probe was employed for naked eye sensing studies over amines and anions. The push-pull electron motion makes the probe completely soluble in water without any complication in sensing studies under aqueous medium. Selectivity experiment of probe $(50 \mu \mathrm{M})$ was carried out with various analytes $(50 \mu \mathrm{M})$ including amines and anions under aqueous medium. It yields selective response with hydrazine under aqueous medium with colour change from colourless to pink colour (Fig.1). The probe yields distinct colour change with hydrazine within 2 minutes of reaction time. The colour change was due to the formation of bright chromophore after reaction with hydrazine.

\section{2. Photophysical studies}

The absorbance spectrum of the probe was collected using Shimadzu UV-2600 spectrophotometer. The selectivity experiment of probe with various analytes in complete aqueous medium was carried out and respective absorption spectrum was recorded. Addition of 2 eq. of hydrazine causes colour change from colourless to pink and forms new absorption peak at $525 \mathrm{~nm}$. Other analytes does not evince any characteristic change in absorption spectrum of the probe as they do not interact with probe and doesn't have any characteristic colour change even with addition of 10 eq. The absorbance change for hydrazine detection was ratiometric with isosbestic point at $450 \mathrm{~nm}$ (Fig. 2). The addition of hydrazine evinced abrupt response in absorbance change with intense pink colour.

\section{3. Selectivity and sensitivity experiment}

The selectivity was further verified with competing interferents in order to achieve selective detection of hydrazine in the environment. The interference effect of other analytes such as aliphatic and aromatic amines and diamines, ammonia and reactive anions were verified. To the probe solution $\left(50 \mu \mathrm{M}\right.$ in $\left.\mathrm{H}_{2} \mathrm{O}\right)$ various analytes (10 eq.) were added and the absorbance at $525 \mathrm{~nm}$ was measured. To that solution 2 eq. of hydrazine was added and the absorbance changes at $525 \mathrm{~nm}$ was measured again. It is obvious 
that addition of other analytes with probe does not have much effect and it does not yield any absorbance change at $525 \mathrm{~nm}$ (Fig. 3 (Black bar)). Addition of

hydrazine to the probe in the presence of other interferents causes distinct absorbance change at $525 \mathrm{~nm}$ and none of the analytes interfere with the sensing of probe towards hydrazine (Fig. 3 (Red bar)). The hydrazine undergoes nucleophilic addition at the trigger site and forms chromophore that is deep pink colour. The reaction was very fast and estimated to be completed within few minutes. In order to understand the reaction ability further in detail, we carried out gradual addition of hydrazine to the probe and respective absorbance was measured using spectrophotometer. It is inferred that the probe reacts extremely fast with hydrazine for each addition. The absorbance at $386 \mathrm{~nm}$ got decreased with increasing concentration of hydrazine and peak at $525 \mathrm{~nm}$ getting increased with increasing concentration of hydrazine and saturated with the addition of 1 eq. of hydrazine (Fig. 4). It reveals that 1 eq. of hydrazine is enough to complete the reaction with probe.

Further, absorbance at $386 \mathrm{~nm}$ and $525 \mathrm{~nm}$ was plotted together against increasing the concentration of hydrazine to monitor the ratiometric change of the probe with increasing concentration of hydrazine. Linear increase and decrease was observed for the probe at two different wavelength (Fig. 4 inset).

\section{4. Kinetics experiment}

Abrupt response makes much attention on this probe to make real time working tool for practical sensing application of hydrazine. The reaction time was monitored using UV-Vis spectrometer with increasing reaction time. To probe $(50 \mu \mathrm{M})$ hydrazine was added $(100 \mu \mathrm{M})$ and absorbance was measured with interval of 1 minute for 15 minutes. The absorbance at $386 \mathrm{~nm}$ decreased with increasing time; and absorbance at $525 \mathrm{~nm}$ was increased with respect to time and reaches maximum within few minutes (Fig. 5). The absorbance attains almost maximum intensity within 5 minutes. The absorbance change at $386 \mathrm{~nm}$ and $525 \mathrm{~nm}$ was monitored by single plot in order to notice the ratiometric changes of probe with hydrazine over time. The increasing and decreasing of absorbance happens within two minutes and reaches almost maximum (Fig. 5 inset).

\section{5. Real time application}

The probe evinces eye catching colorimetric response towards hydrazine with immediate response. We want to utilize promising response of the probe towards hydrazine sensing to make a practical tool to detect hydrazine in real time. In prior to that, the limit of detection was calculated using linear plot method. The LOD was calculated as $97 \mathrm{nM}(\sim 3 \mathrm{ppb})$ (Fig. S6). The results of the probe was verified with reported probes and tabulated (Table. S1) [34-40]. Compared to the previous reports our probe stands superior in selectivity, reaction time and detection limit under complete aqueous medium.

\section{6. Strip test}

As it can detect nanomolar level hydrazine under complete aqueous medium, real time sensing of hydrazine with small tool was planned. In that motive, paper based test strip were prepared using filter 
paper and soaked into the aqueous solution of probe and dried at room temperature. The prepared paper strips were utilized like a litmus paper to detect hydrazine under aqueous medium and vapour phase. The strips were tested for the detection of hydrazine under aqueous medium. The strips were soaked into increasing concentration of hydrazine in aqueous solution and the colour change was monitored after 2 minutes. The strip yields distinct colour change with respect to increasing concentration of hydrazine (Fig. 6). In second case, the hydrazine vapour was allowed to react with test strip and the changes were monitored. The test strips were pasted inside the glass vial cap containing test solution ( $1 \%$ hydrazine) and the colour change was monitored with increasing reaction time. We can see the appearance of pink colour due to reaction of probe with hydrazine vapour with increasing reaction time (Fig. 7). The hydrazine vapour reacts with the probe and makes colour change in the strip. The probe yields excellent response towards hydrazine under aqueous and vapour phase hydrazine detection.

\section{7. Spray test}

The sensing applications were extended towards hydrazine in real time monitoring. Spray based sensing of hydrazine was demonstrated using probe $\mathrm{CyNH}$ (Fig. 8). In prior to that, hydrazine contaminated strips were prepared using whatman filter paper with drop of $0.1 \%$ hydrazine in double distilled water and the contamination spots were marked with pen. The test strip was sprayed with $\mathrm{CyNH}$ ( $50 \mu \mathrm{M}$ in water) and immediate colour change was observed on the hydrazine contamination spot (Fig. 9). The colour change was quick and distinct with bright pink colour though we can monitor the changes with our naked eye without aid of any external instruments. The probe yields simple and effective response with hydrazine monitoring in real time with onsite information.

\section{8. Soil analysis}

In order to observe the toxic chemical contamination in the environment we performed soil analysis for the detection of hydrazine in the soil. Initially, grounded field soil were pre-treated with different concentration of hydrazine $(0.001,0.005,0.01,0.05,0.1,0.5$ and $1 \%)$ in double distilled water and dried

under room temperature (Fig. 10 (a)). Hydrazine pre-treated soils ( $1 \mathrm{~g})$ were added to the probe solution ( $50 \mu \mathrm{M}$ in water) and the changes were monitored. Interestingly, hydrazine pre-treated soil yields immediate colour change with probe within 2 mins with distinct colour change (Fig. 10 (b)). The intensity of the colour change was increased with increasing concentration of hydrazine. The absorbance for the respective soil samples were measured. The absorbance at $525 \mathrm{~nm}$ was increased

with increasing concentration of hydrazine and reaches maximum with addition of $0.05 \%$ of hydrazine and remains constant with higher concentration (Fig. 10 (c)). We can monitor lower concentration upto $0.001 \%$ hydrazine in soil with distinct colour change. The results evinces effective detection of hydrazine in soil samples with rapid colour change.

\section{Conclusion}


In summary, water soluble probe $(\mathrm{CynH})$ was designed and synthesised for detection of hydrazine under complete aqueous medium. Synthesised probe was successfully characterized by NMR and mass spectroscopic technique. The probe evinces eye catching sensing output towards hydrazine with the presence of other competing analytes under complete aqueous medium. The response with hydrazine was quick with distinct colour change. It yields sensitive response with hydrazine with LOD and LOQ 97 nM. Quick and sensitive response of the probe was utilized effectively to monitor the hydrazine in realtime with paper based test strip under aqueous and vapour phase. The application was extended to monitor the hydrazine using spray method. For the environmental protection concern, the hydrazine contamination was monitored via soil test with probe solution. In summary, probe evinces better sensing application for hydrazine that can overcome the limitations of previous reports and can serve as good sensor for hydrazine in real time sensing application.

\section{Declarations}

\section{Consent to participate}

A statement regarding informed consent is not applicable.

\section{Consent for publication}

A statement regarding informed consent is not applicable.

\section{Code availability}

Not applicable

\section{Authors' contributions}

Sivan Velmathi contributed to the conception of the study and wrote the manuscript and Natarajan Vijay performed all the experiments and analysis and wrote the manuscript

\section{Funding}

'Not applicable'

\section{Conflicts of interest/Competing interests}

'Not applicable'

\section{Availability of data and material}

Electronic supporting information file is available for synthesis procedure, NMR and MS analysis 


\section{Code availability}

'Not applicable

\section{References}

1. Rosca, V.; Koper, M. T. (2008) Electrocatalytic oxidation of hydrazine on platinum electrodes in alkaline solutions. Electrochim. Acta., 53:5199-5205. https://doi.org/ 10.1016/j.electacta.2008.02.054.

2. Yu, L.; Zhang, X.; Yu, L., (2014) On-line Determination of Hydrazine in Environmental Water by Reference Flow Injection Analysis. Communications in Information Science and Management Engineering., 4: 13, Book series, $1^{\text {st }}$ edition, CRC press Taylor and francis, Editor: Garry Lee, Hong Kong.

3. Khaled, K., (2006) Experimental and theoretical study for corrosion inhibition of mild steel in hydrochloric acid solution by some new hydrazine carbodithioic acid derivatives. Appl. Surf. Sci., 252:4120-4128. https://doi.org/10.1016/j.apsusc.2005.06.016.

4. Zelnick, S. D.; Mattie, D. R.; Stepaniak, P. C., (2003) Occupational exposure to hydrazines: treatment of acute central nervous system toxicity. Aviat. Space Environ. Med., 74:1285-1291.

5. Yin, W. X.; Li, Z. P.; Zhu, J. K.; Qin, H. Y., (2008) Effects of $\mathrm{NaOH}$ addition on performance of the direct hydrazine fuel cell. J. Power Sources., 182:520-523.

https://doi.org/ 10.1016/j.jpowsour.2008.04.028.

6. Aigner, B.; Darsow, U.; Grosber, M.; Ring, J.; Plötz, S., (2010) Multiple basal cell carcinomas after long-term exposure to hydrazine: Case report and review of the literature. Dermatology., 221:300-302. https://doi.org/10.1159/000321338.

7. Garrod, S.; Bollard, M. E.; Nicholls, A. W.; Connor, S. C.; Connelly, J.; Nicholson, J. K.; Holmes, E., (2005) Integrated metabonomic analysis of the multiorgan effects of hydrazine toxicity in the rat. Chem. Res. Toxicol., 18:115-122. https://doi.org/ 10.1021/tx0498915.

8. Umar, A.; Rahman, M. M.; Kim, S. H.; Hahn, Y.-B., (2008) Zinc oxide nanonail based chemical sensor for hydrazine detection. Chem. Comm., 2:66-168. https://doi.org/10.1039/B711215G.

9. $\quad$ Cruz Vieira, l.; Omuro Lupetti, K.; Fatibello-Filho, O., (2002) Sweet potato (Ipomoea batatas (L.) Lam.) tissue as a biocatalyst in a paraffin/graphite biosensor for hydrazine determination in boiler feed water. Anal. Lett., 35:2221-2231. https://doi.org/ 10.1081/AL-120016097.

10. Reilly, C. A.; Aust, S. D., (1997) Peroxidase substrates stimulate the oxidation of hydralazine to metabolites which cause single-strand breaks in DNA. Chem. Res. Toxicol., 10:328-334. https://doi.org/ 10.1021/tx960189l. 
11. Leakakos, T.; Shank, R. C., (1994) Hydrazine genotoxicity in the neonatal rat. Toxicol. Appl. Pharm., 126:295-300. https://doi.org/ 10.1006/taap.1994.1119.

12. Noda, A.; Ishizawa, M.; Ohno, K.; Sendo, T.; Noda, H., (1986) Relationship between oxidative metabolites of hydrazine and hydrazine-induced mutagenicity. Toxicol. Lett., 31:131-137. https://doi.org/ 10.1016/0378-4274(86)90006-8.

13. Vivekanandan, P.; Gobianand, K.; Priya, S.; Vijayalakshmi, P.; Karthikeyan, S., (2007) Protective effect of picroliv against hydrazine-induced hyperlipidemia and hepatic steatosis in rats. Drug. Chem. Toxicol., 30:241-252. https://doi.org/ 10.1080/01480540701375216.

14. Oh, J.-A.; Park, J.-H.; Shin, H.-S., (2013) Sensitive determination of hydrazine in water by gas chromatography-mass spectrometry after derivatization with ortho-phthalaldehyde. Anal. Chim. Acta., 769:79-83. https://doi.org/10.1016/j.aca.2013.01.036.

15. Liu, J.; Li, Y.; Jiang, J.; Huang, X., (2010) C@ ZnO nanorod array-based hydrazine electrochemical sensor with improved sensitivity and stability. Dalton Trans., 39:8693-8697. https://doi.org/10.1039/CODT00258E.

16. Li, Y.; Deng, C.; Yang, M., (2014) Facilely prepared composites of polyelectrolytes and graphene as the sensing materials for the detection of very low humidity. Sensors. Actuat. B: Chem., 194:5158. https://doi.org/10.1016/j.snb.2013.12.080

18. Qian, Y.; Lin, J.; Han, L.; Lin, L.; Zhu, H., (2014) A resorufin-based colorimetric and fluorescent probe for live-cell monitoring of hydrazine. Biosens. Bioelectron., 58:282-286. https://doi.org/10.1016/j.bios.2014.02.059.

19. Goswami, S.; Paul, S.; Manna, A., (2015) Fast and ratiometric "naked eye" detection of hydrazine for both solid and vapour phase sensing. New J. Chem., 39:2300-2305. https://doi.org/ 10.1039/C4NJ02220C.

20. Batchelor-McAuley, C.; Banks, C. E.; Simm, A. O.; Jones, T. G.; Compton, R. G., (2006) The electroanalytical detection of hydrazine: a comparison of the use of palladium nanoparticles supported on boron-doped diamond and palladium plated BDD microdisc array. Analyst., 131:106-110. https://doi.org/10.1039/B513751A.

21. Bhutani, H.; Singh, S.; Vir, S.; Bhutani, K.; Kumar, R.; Chakraborti, A. K.; Jindal, K., (2007) LC and LC-MS study of stress decomposition behaviour of isoniazid and establishment of validated stabilityindicating assay method. J. Pharmaceut. Biomed., 43:1213-1220. https://doi.org/10.1016/j.jpba.2006.10.013.

21. Li, K.; Xu, H.-R.; Yu, K.-K.; Hou, J.-T.; Yu, X.-Q., (2013) A coumarin-based chromogenic and ratiometric probe for hydrazine. Anal. Methods., 5:2653-2656. https://doi.org/10.1039/C3AY40148K 
22. Zhang, J.; Ning, L.; Liu, J.; Wang, J.; Yu, B.; Liu, X.; Yao, X.; Zhang, Z.; Zhang, H., (2015) Nakedeye and near-infrared fluorescence probe for hydrazine and its applications in in vitro and in vivo bioimaging. Anal. Chem., 87:9101-9107. https://doi.org/10.1021/acs.analchem.5b02527.

23. Sun, M.; Bai, L.; Liu, D. Q., (2009) A generic approach for the determination of trace hydrazine in drug substances using in situ derivatization-headspace GC-MS. J. Pharmaceut. Biomed., 49:529-533. https://doi.org/10.1016/j.jpba.2008.11.009.

24. Choi, M. G.; Hwang, J.; Moon, J. O.; Sung, J.; Chang, S.-K., (2011) Hydrazine-selective chromogenic and fluorogenic probe based on levulinated coumarin. Org. Lett., 13:5260-5263. https://doi.org/10.1021/ol202136q.

25. Zhu, S.; Lin, W.; Yuan, L., (2013) Development of a near-infrared fluorescent probe for monitoring hydrazine in serum and living cells. Anal. Methods., 5:3450-3453. https://doi.org/10.1039/C3AY40540K.

26. Cui, L.; Peng, Z.; Ji, C.; Huang, J.; Huang, D.; Ma, J.; Zhang, S.; Qian, X.; Xu, Y., (2014) Hydrazine detection in the gas state and aqueous solution based on the Gabriel mechanism and its imaging in living cells. Chem. Comm., 50:1485-1487. https://doi.org/10.1039/C3CC48304E.

27. Xiao, L.; Tu, J.; Sun, S.; Pei, Z.; Pei, Y.; Pang, Y.; Xu, Y., (2014) A fluorescent probe for hydrazine and its in vivo applications. RSC Adv., 4:41807-41811. https://doi.org/10.1039/C4RA08101C.

28. Fan, J.; Sun, W.; Hu, M.; Cao, J.; Cheng, G.; Dong, H.; Song, K.; Liu, Y.; Sun, S.; Peng, X., (2012) An ICT-based ratiometric probe for hydrazine and its application in live cells. Chem. Comm., 48:81178119. https://doi.org/10.1039/C2CC34168A.

29. Oyefusi, A.; Olanipekun, O.; Neelgund, G. M.; Peterson, D.; Stone, J. M.; Williams, E.; Carson, L.; Regisford, G.; Oki, A., (2014) Hydroxyapatite grafted carbon nanotubes and graphene nanosheets: Promising bone implant materials. Spectrochimica Acta Part A: Molecular and Biomolecular Spectroscopy., 132:410-416. https://doi.org/10.1016/j.saa.2014.04.004

30. Sun, M.; Guo, J.; Yang, Q.; Xiao, N.; Li, Y., (2014) A new fluorescent and colorimetric sensor for hydrazine and its application in biological systems. J. Mater. Chem. B., 2:1846-1851. https://doi.org/10.1039/C3TB21753A.

31. Tse, H.; Li, Q.; Chan, S.; You, Q.; Lee, A. W.; Chan, W., (2016) A ratiometric fluorescent and colorimetric probe for selective detection of hydrazine. RSC Adv., 6:14678-14681. https://doi.org/10.1039/C5RA26683A.

32. Ruan, S.; Gao, Y.; Wang, Y.; Li, M.; Yang, H.; Song, J.; Wang, Z.; Wang, S., (2020) A novel berberine-based colorimetric and fluorimetric probe for hydrazine detection. New J. Chem., 44:1575215757. https://doi.org/10.1039/D0NJ03599H. 
33. Fraga-Corral, M.; Carpena, M.; Garcia-Oliveira, P.; Pereira, A.; Prieto, M.; Simal-Gandara, J., (2020) Analytical metabolomics and applications in health, environmental and food science. Crit. Rev. Anal. Chem., 1-23. https://doi.org/10.1080/10408347.2020.1823811.

34. Mahapatra, A. K.; Maji, R.; Maiti, K.; Manna, S. K.; Mondal, S.; Ali, S. S.; Manna, S.; Sahoo, P.; Mandal, S.; Uddin, M. R., (2015) A BODIPY/pyrene-based chemodosimetric fluorescent chemosensor for selective sensing of hydrazine in the gas and aqueous solution state and its imaging in living cells. RSC. Adv., 5:58228-58236. https://doi.org/10.1039/C5RA10198K

35. Ju, Z.; Li, D.; Zhang, D.; Li, D.; Wu, C.; Xu, Z., (2017) An ESIPT-based fluorescent probe for hydrazine detection in aqueous solution and its application in living cells. J. Fluoresce., 27:679687. https://doi.org/10.1007/s10895-016-1997-7

36. Hao, Y.; Zhang, Y.; Ruan, K.; Chen, W.; Zhou, B.; Tan, X.; Wang, Y.; Zhao, L.; Zhang, G.; Qu, P., (2017) A naphthalimide-based chemodosimetric probe for ratiometric detection of hydrazine. Sensors. Actuat. B: Chem., 244:417-424. https://doi.org/10.1016/j.snb.2016.12.145

37. Sun, Y.; Zhao, D.; Fan, S.; Duan, L., (2015) A 4-hydroxynaphthalimide-derived ratiometric fluorescent probe for hydrazine and its in vivo applications. Sensors. Actuat. B: Chem., 208:512517. https://doi.org/10.1016/j.snb.2014.11.057

38. Liu, C.; Wang, F.; Xiao, T.; Chi, B.; Wu, Y.; Zhu, D.; Chen, X., (2018) The ESIPT fluorescent probes for $\mathrm{N} 2 \mathrm{H} 4$ based on benzothiazol and their applications for gas sensing and bioimaging. Sensors. Actuat. B: Chem., 256:55-62. https://doi.org/10.1016/j.snb.2017.09.198

39. Ran, Y.-Z.; Xu, H.-R.; Li, K.; Yu, K.-K.; Yang, J.; Yu, X.-Q., (2016) Development of a mitochondriatargeted fluorescent probe for hydrazine monitoring in living cells. RSC Adv., 6:111016111019. https://doi.org/10.1039/C6RA24110G

40. Ma, J.; Fan, J.; Li, H.; Yao, Q.; Xia, J.; Wang, J.; Peng, X., (2017) Probing hydrazine with a nearinfrared fluorescent chemodosimeter. Dyes. Pigment., 138:39-

46. https://doi.org/10.1016/j.dyepig.2016.11.026

\section{Figures}

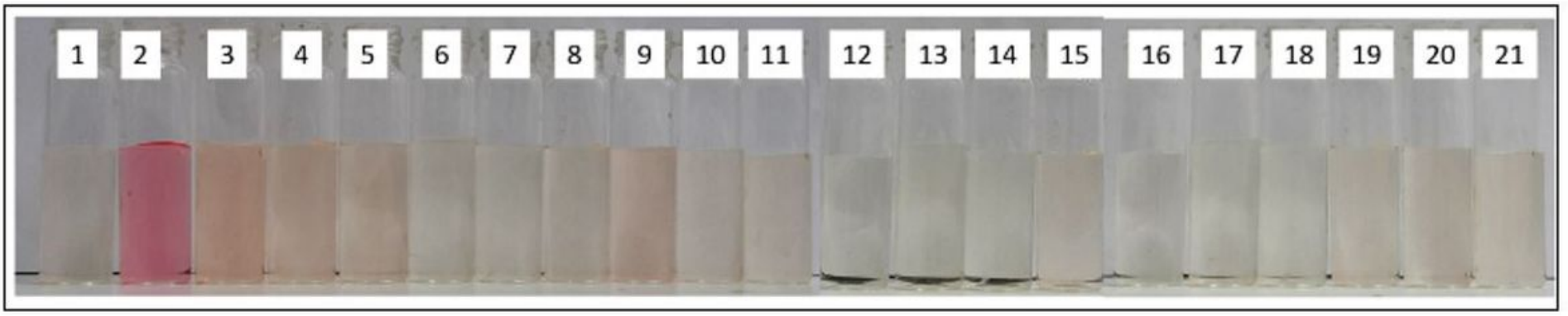


Figure 1

Naked eye colour change experiment of probe $(\mathrm{CynH})(50 \mu \mathrm{M})$ towards analytes $(100 \mu \mathrm{M}$ Hydrazine and $500 \mu \mathrm{M}$ of other analytes) in water $(3 \mathrm{~mL})$ [Analytes: 1. Probe, 2. Hydrazine, 3. Ethylenediamine, 4. 1,3Diaminopropane, 5. 1.4-Diaminobutane, 6. 0-Phenylene diamine, 7. Aniline, 8. Methylamine, 9. NButylamine, 10. Phenylhydrazine, 11. Ammonia, 12. CN-, 13. F-, 14. Cl-, 15. Br-, 16. I-, 17. -OAc, 18. H2PO4-, 19. HSO4-, 20. NO3-, 21. -OH].

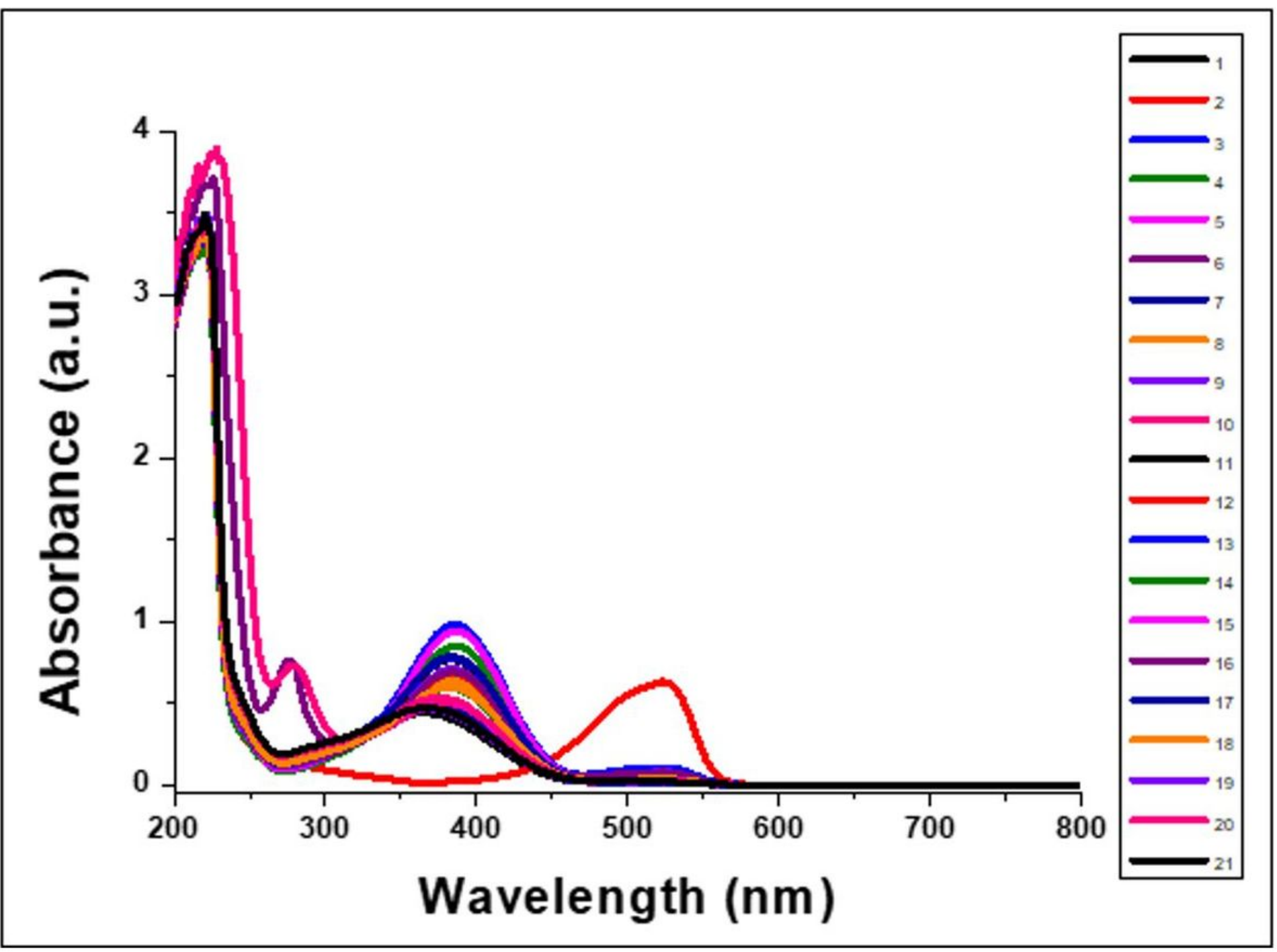

Figure 2

UV-Visible spectrum of probe $\mathrm{CynH}(50 \mu \mathrm{M})$ with analytes $(100 \mu \mathrm{M}$ hydrazine and $500 \mu \mathrm{M}$ of other analytes) in water (3 $\mathrm{mL})$. [Analyte details are provided in Figure. 1]. 


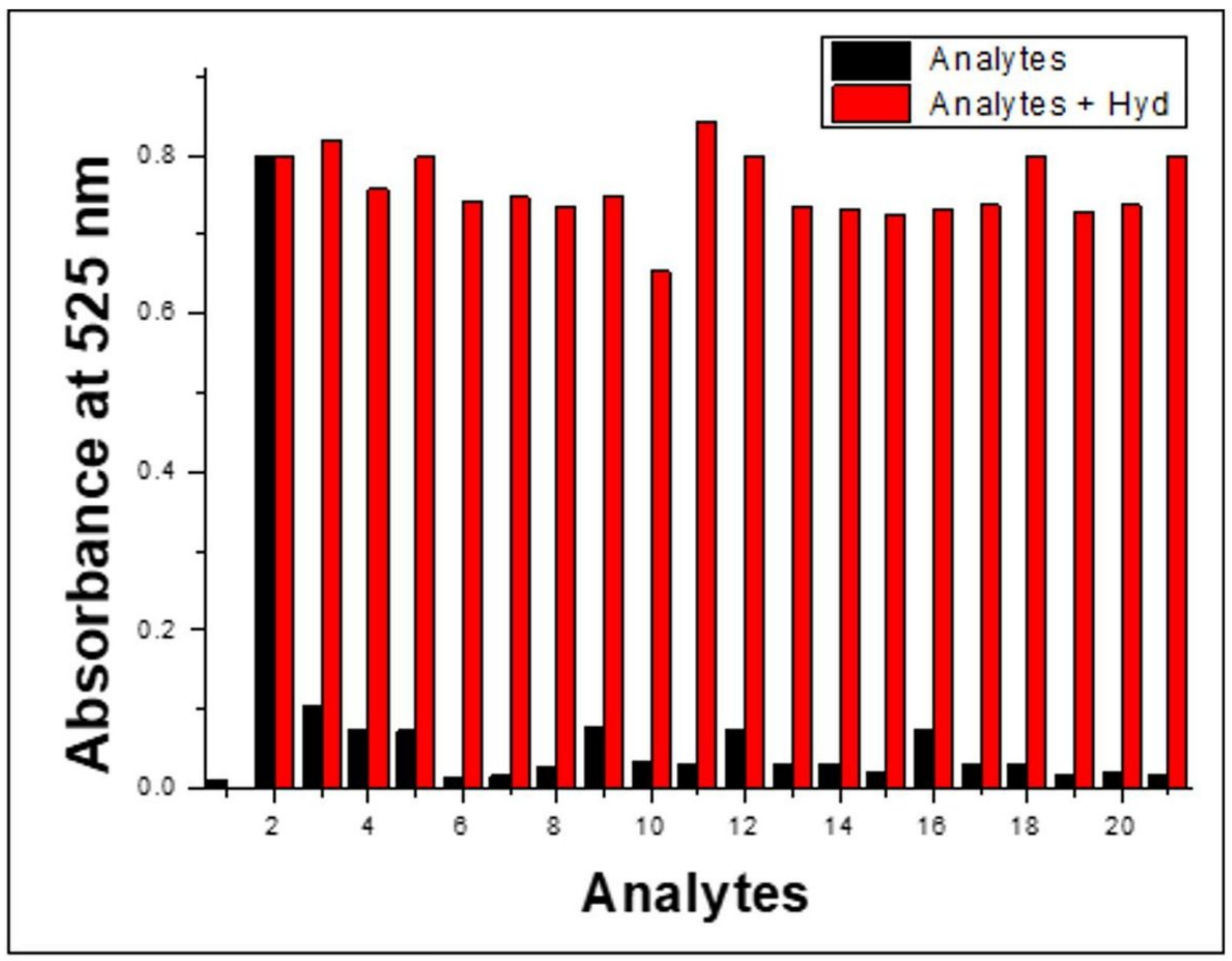

Figure 3

Absorbance change at $525 \mathrm{~nm}$ probe $\mathrm{CyNH}(50 \mu \mathrm{M})$ added with hydrazine (2 eq.) and other analytes (10 eq.) in water (Black bar: Absorption of probe $\mathrm{CyNH}$ with analytes; Red bar: Absorption changes of probe CyNH with competing analytes (10eq.) and hydrazine (2 eq.)). 


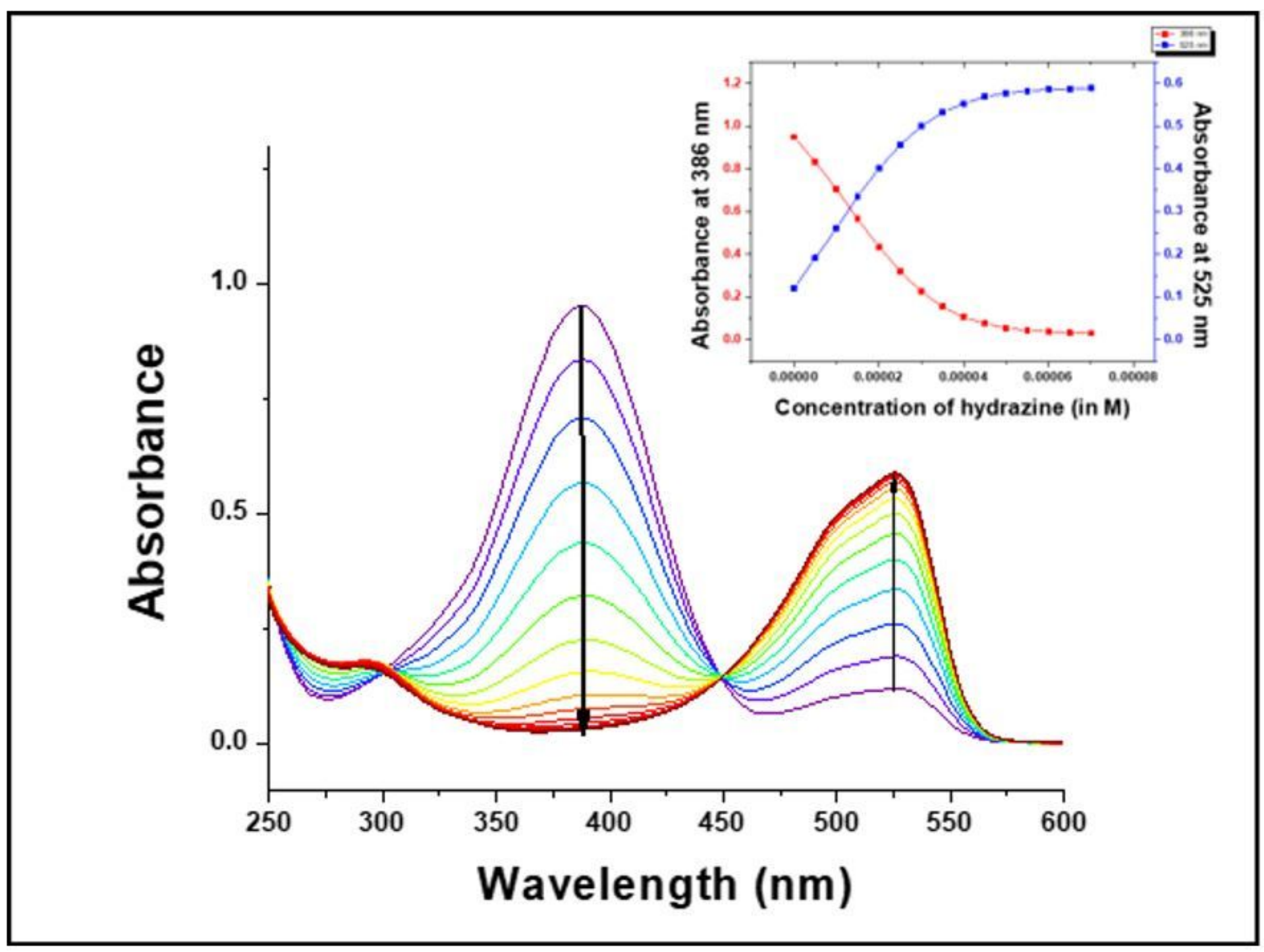

Figure 4

Incremental addition of hydrazine $(0-100 \mu \mathrm{M})$ to probe $\mathrm{CynH}(50 \mu \mathrm{M})$ in water $(3 \mathrm{~mL})$ 


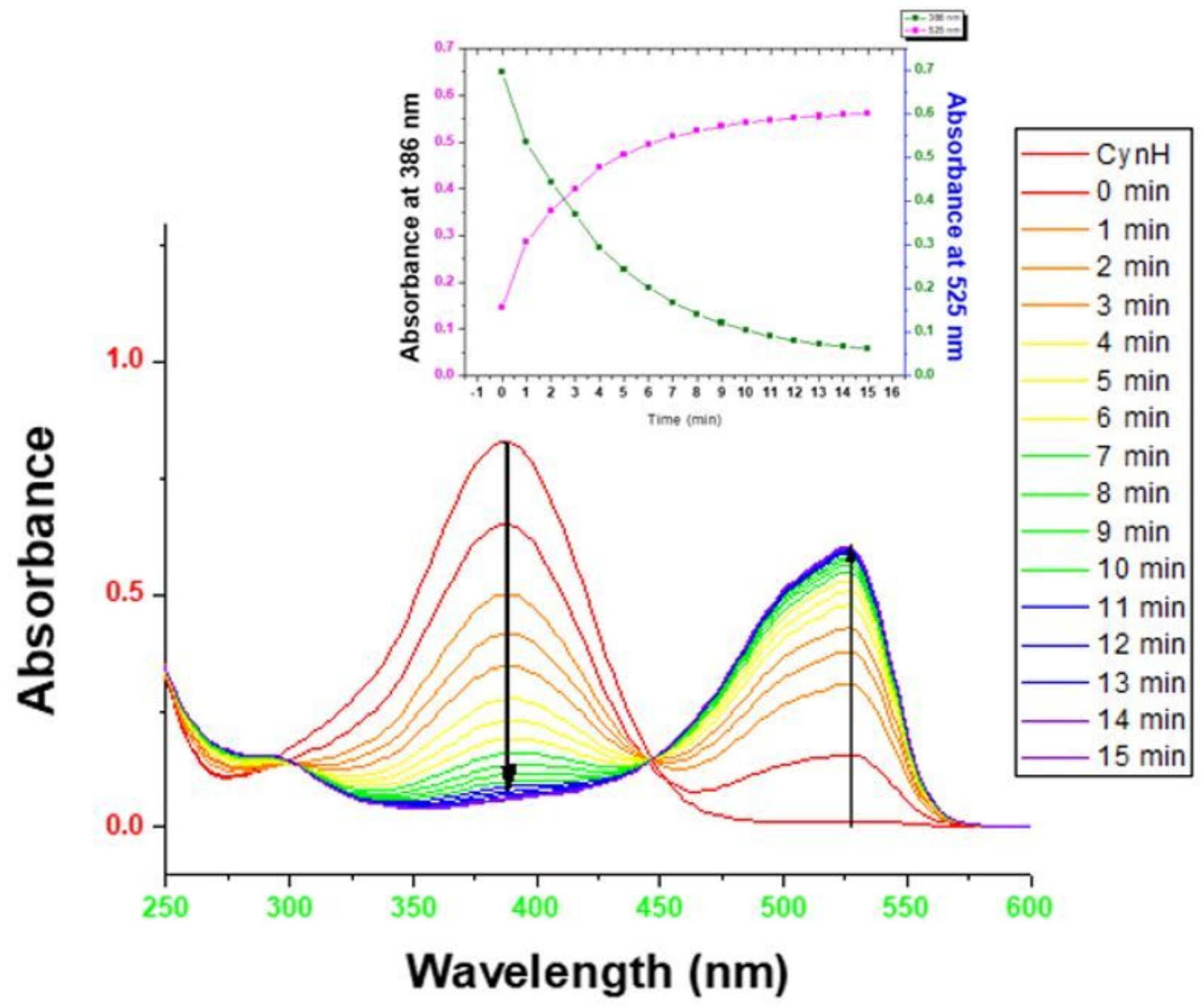

Figure 5

Absorption changes of probe $\mathrm{CynH}(50 \mu \mathrm{M})$ with hydrazine $(100 \mu \mathrm{M})$ upon increasing time in water (3 $\mathrm{mL})$

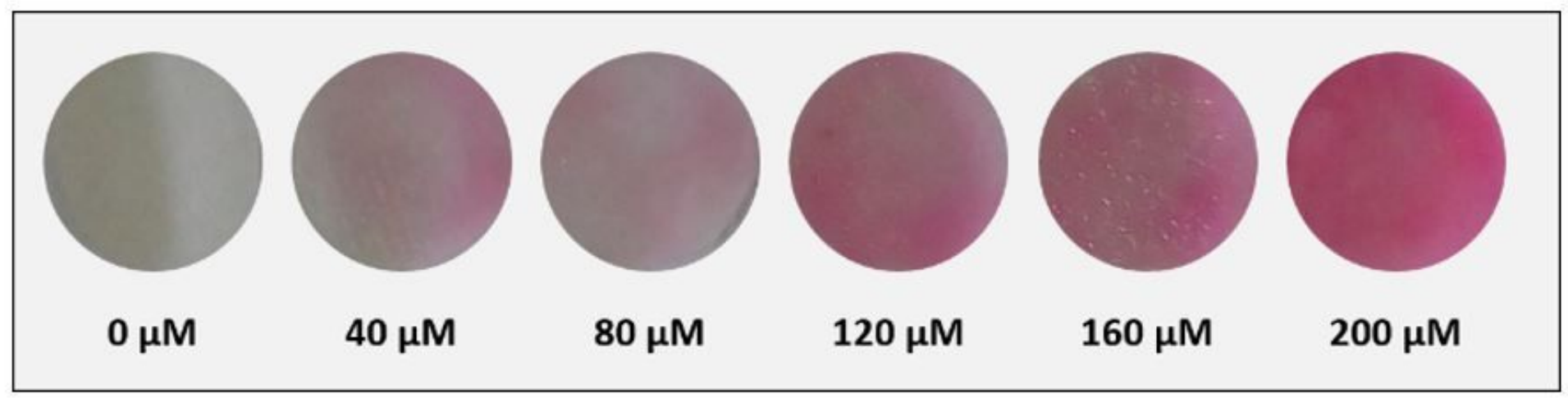

Figure 6 
Strip treated with probe $\mathrm{CynH}(50 \mu \mathrm{M})$ with increasing concentration of hydrazine $(0-200 \mu \mathrm{M})$

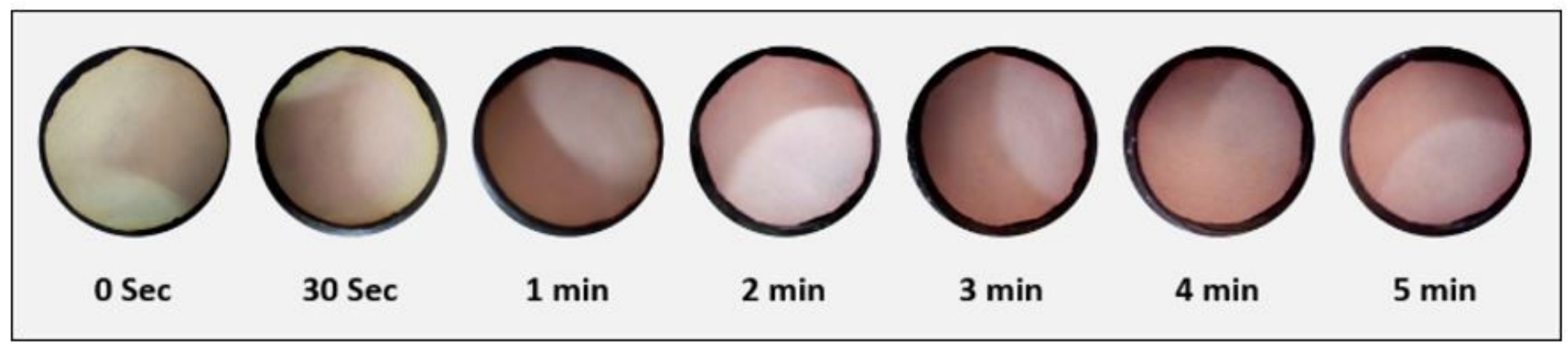

\section{Figure 7}

Probe treated strips for detection of hydrazine vapour (1\%) with increasing time

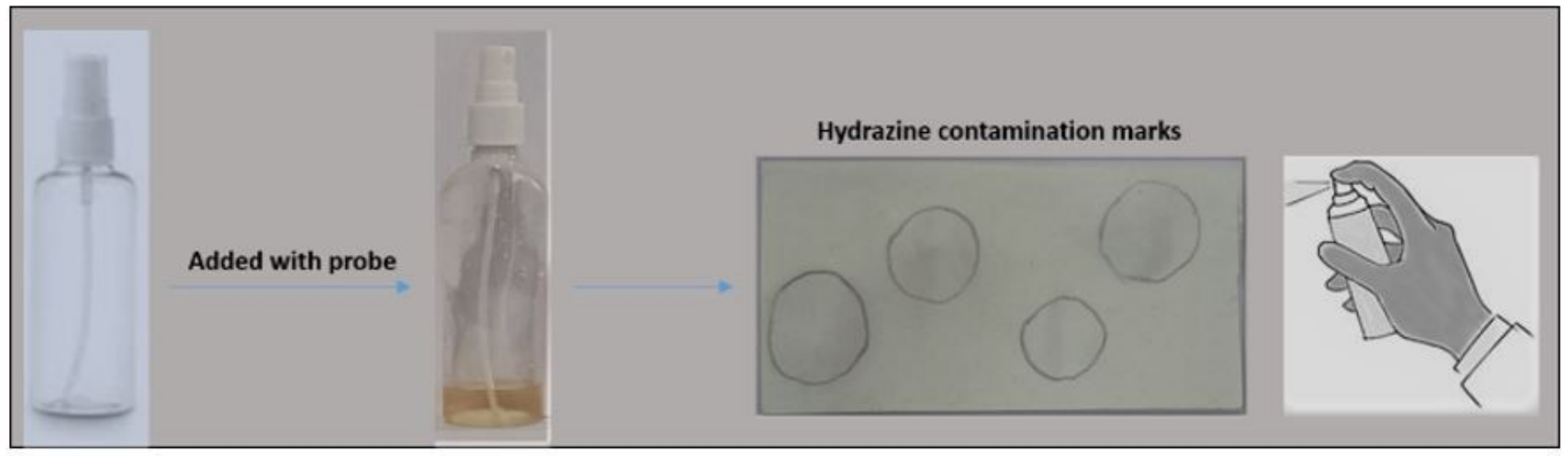

\section{Figure 8}

Schematic illustration of spray test experiment

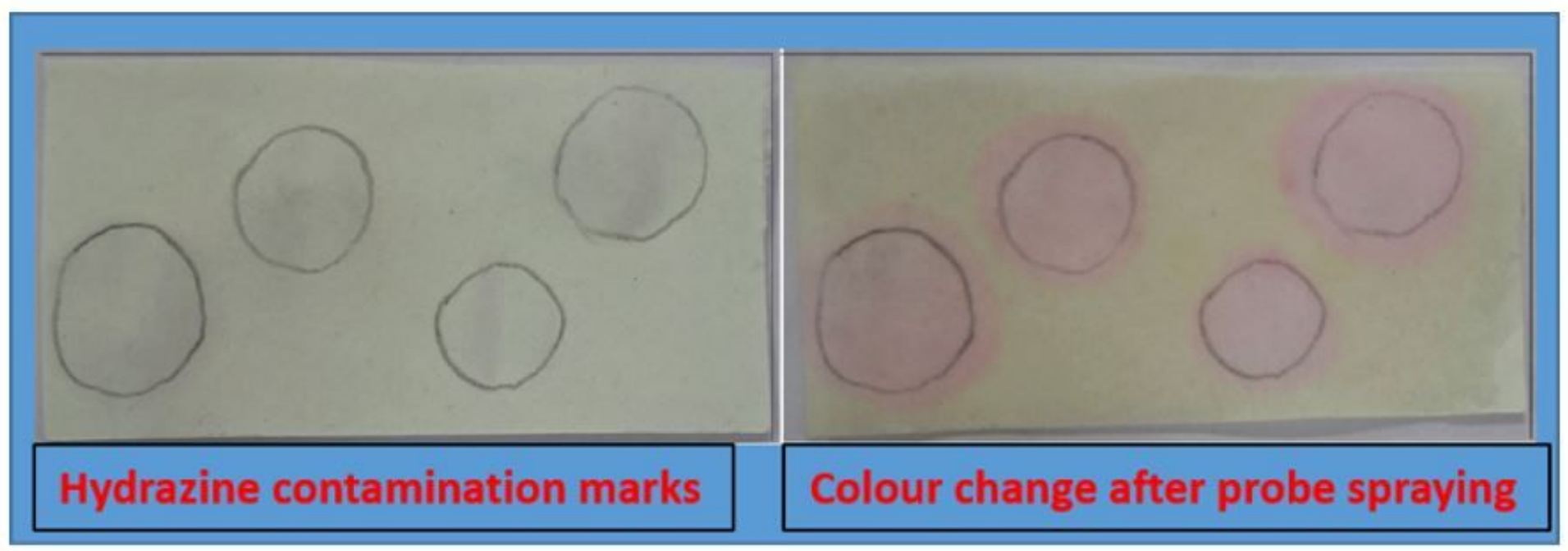

\section{Figure 9}


Colour change experiment of spray test of test strip with hydrazine contamination (0.1\%) immediately after spraying of probe $(50 \mu \mathrm{M})$

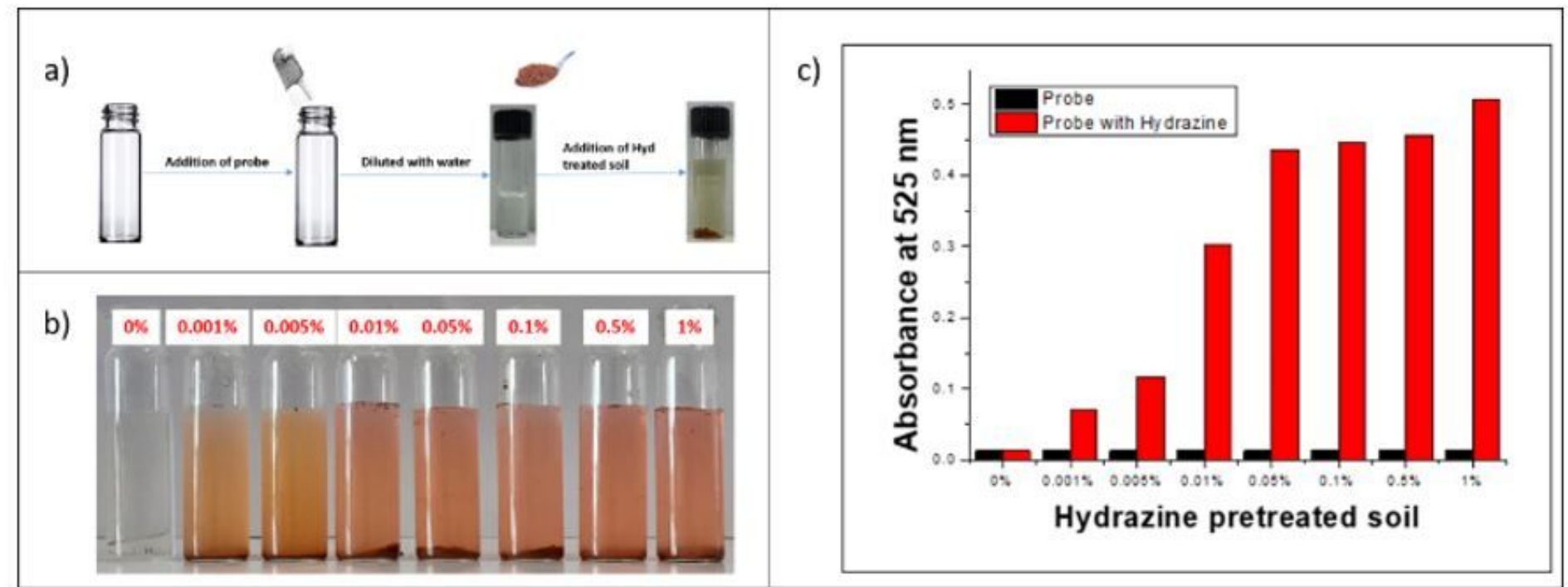

Figure 10

a) Schematic illustration of soil analysis of hydrazine with probe $\mathrm{CyNH}$; b) Naked eye colour change of probe $(50 \mu \mathrm{M})$ with hydrazine pre-treated soils (Concentration: $0.001 \%$ to $1 \%$ ); c) Absorbance change at $525 \mathrm{~nm}$ for probe with hydrazine pre-treated soils.

\section{Supplementary Files}

This is a list of supplementary files associated with this preprint. Click to download.

- scheme1.jpg

- scheme2.jpg

- scheme3.jpg

- ESI.docx 